\title{
A NOVA LEI DE MIGRAÇÃO E OS TRATADOS INTERNACIONAIS DE DIREITOS HUMANOS DAS AMERICAS COMO MEIOS DE PROTEÇÃO DA DIGNIDADE HUMANA DE MIGRANTES NO BRASIL
}

\author{
Edyleno Italo Santos Sodré* \\ Mario Jorge Philocreon de Castro Lima**
}

\begin{abstract}
RESUMO: A nova Lei de Migração brasileira consiste em instrumento legal oportuno em favor de tratamento mais digno aos não nacionais que se encontram em território brasileiro em situação duradoura tangidos pelas aflições nos seus países de origem. A Lei de Migração se integra com normas constitucionais e internacionais de direitos humanos compulsórios ao Brasil, aderente da Convenção Americana de Direitos Humanos da OEA e da Corte Interamericana dos Direitos Humanos. Essa adesão imputa responsabilidade ao Brasil de garantir tratamento digno às populações de deslocados, refugiados e apátridas que acorrem ao território brasileiro em tempos recentes.
\end{abstract}

PALAVRAS - CHAVE: Lei de Migração; Tratados Internacionais; Direitos Humanos

\section{THE NEW MIGRATION LAW AND THE INTERNATIONAL TREATIES ON HUMAN RIGHTS IN THE AMERICAS AS MEANS TO PROTECT THE HUMAN DIGNITY OF MIGRANTS IN BRAZIL}

\begin{abstract}
The new Brazilian Migration Law is an opportune legal instrument in favor of more dignified treatment to non-nationals who are in Brazilian territory in a lasting situation affected by the afflictions in their original countries. The Migration Law is integrated with constitutional and international human rights norms that are compulsory for Brazil, adhering to the American Convention on Human Rights of the OAS and the Inter-American Court of Human Rights. This adhesion imputes responsibility to Brazil to guarantee dignified treatment to the populations of displaced people, refugees and stateless persons who have flowed to brazilian territory in recent times.
\end{abstract}

KEYWORDS: Migration Law; International Treaties; Human Rights

\section{INTRODUÇÃO}

A edição da Lei $n^{o}$ 13.445/2017, nova Lei de Migração e de seu regulamento, Decreto $\mathrm{n}^{\circ} 9.199 / 2017$, que substituíram a obsoleta lei $\mathrm{n}^{\circ} 6.815 / 1980$, denominada como

\footnotetext{
* Doutorando em Direito pela Universidade Federal da Bahia - UFBA. Mestre em Constitucionalização do Direito, pela Universidade Federal de Sergipe - UFS. Especialista em Direito Público pela Universidade do Sul de Santa Catarina - UNISUL. Promotor de Justiça do Estado de Sergipe. edyleno@hotmail.com; Orcid: http://0000-0002-9996-0209; CV: http://lattes.cnpq.br/8953882150400232.

** Doutor em Direito pela Universidade Federal de Pernambuco-UFPE. Mestre em Direito pela Universidade Federal da Bahia-UFBA. Mestre em Administração pela Universidade Federal da Bahia-UFBA. Procurador da Fazenda Nacional aposentado. Professor Associado da Faculdade de Direito da Universidade Federal da BahiaUFBA. malima@ufba.br; Orcid:http://0000-0001-9670-435X; CV:http://lattes.cnpq.br/2759364549381451.
} 
Estatuto do Estrangeiro, consistiu em significativa atualização do ordenamento normativo brasileiro, em busca de melhor harmonia com os princípios da Constituição de 1988, bem como com os tratados internacionais humanistas dos quais o Brasil é participante.

Dentre os tratados humanistas se destaca a posição do Estado brasileiro como integrante da Organização dos Estados Americanos - OEA, e aderente específico de sua Convenção Americana de Direitos Humanos - $\mathrm{CADH}$, bem como submetido às diretrizes, orientações e determinações da Corte Interamericana dos Direitos Humanos - CIDH, órgão consultivo e judiciário da OEA nessa matéria.

A participação inarredável do Estado Brasileiro perante os tratados humanistas se torna mais relevante quando se observa as circunstâncias que afligem a humanidade nos últimos anos, com a emergente crise dos migrantes e refugiados que alcança muitos países em vários continentes, que também tem produzido ocorrências marcantes no Brasil.

Registre-se que no atual cenário global a situação se tornou ainda mais agravada com a chegada da pandemia mundial do coronavirus, uma vez que a contaminação das pessoas no continente sul-americano, principalmente nas comunidades mais carentes, assume dimensões gigantescas, como noticiam canais da imprensa mundial.

Nesse contexto, a nova Lei de Migração brasileira se afirma como instrumento sóciojurídico adequado e oportuno, no sentido de que seja conferido tratamento mais digno aos não nacionais que se encontram em território brasileiro, seja na condição de asilados, refugiados, visitantes temporários, ou mesmo apátridas, isto é, sem vínculo com um país de origem.

Por sua vez, espera-se idêntico tratamento deve ser reservado aos brasileiros que se encontram no solo de outros Estados, considerando-se os princípios basilares da reciprocidade de tratamento e da não devolução, norteador das relações internacionais, que constam de forma mais expressa em inúmeras avenças bilaterais ou multilaterais.

Inspirado na nova Lei de Migração e nos tratados humanistas que o Brasil participa, o presente artigo pretende relembrar um breve histórico das políticas migratórias brasileiras desde os primeiros anos de independência, com o que se pretende percorrer o caminho de verificação das presumidas violações de Direitos Humanos na atualidade.

As metodologias empregadas na elaboração para esse trabalho são a descritiva e a histórica, com recortes específicos em determinados momentos pretéritos e recentes do Estado Brasileiro, partindo do período do império. 
2. O ADVENTO NOVA LEI DE MIGRAÇÃO PARA REGULAR A PRESENÇA DE MIGRANTES NO BRASIL

No cenário regional sul-americano, inclusive o Brasil, as movimentações em larga escala de famílias e até de populações inteiras que deixam seus países e lares e ingressam nos vizinhos fronteiriços têm causado inquietações socais e preocupações institucionais. No Brasil, os estados com fronteiras nacionais terrestres são os mais atingidos, a exemplo de Roraima e Mato Grosso do Sul.

Em atenção ao princípio constitucional da dignidade da pessoa humana, previsto expressamente na Constituição Federal de 1988, o Estado brasileiro não pode simplesmente bloquear as fronteiras e se esquivar de assegurar, durante essas movimentações, um mínimo de condições existenciais não só aos nacionais que moram nos centros urbanos fronteiriços, bem como, em atuação de cooperação internacional, assistir aos numerosos novos migrantes não nacionais ou habitantes provisórios dessas regiões.

A nova Lei de Migração brasileira, lei $n^{\circ} 13.445 / 2017$, regula de modo atualizado a temática do fluxo migratório, entretanto seu regulamento complementar, Decreto $\mathrm{n}^{\circ}$ 9.199, de 20 de novembro de 2017 , veio trazer muitos pontos controvertidos.

Registre-se que a Lei de Migração, editada durante o mandato do Presidente Michel Temer foi sancionada com número significativo de vetos, sendo os principais deles referentes à ocupação de cargo, emprego e função pública por migrantes; concessão automática de residência no país a aprovados em concursos públicos; utilização de serviços públicos de saúde, assistência social e previdência; direito de reunião familiar em casos de outros parentescos, dependência afetiva, ou fatores de sociabilidade; revogação de expulsões anteriores a 1988 e anistia para migrantes ingressados sem documentos até julho de 2016; não expulsão de migrantes residentes no Brasil por mais de 04 (quatro) anos que cometessem crimes; não exigência de prova documental impossível ou descabida que dificulte ou impeça o exercício de seus direitos, inclusive o acesso a cargo, emprego ou função pública; dispensa do serviço militar de brasileiros por opção ou naturalizados que já tenham cumprido suas obrigações militares no país de origem; além da livre circulação de povos indígenas e populações tradicionais em terras ocupadas por seus ancestrais.

Por sua vez, o Decreto Regulamentar, Decreto n 9.199/2017, com 319 artigos, normatizou questões como concessão de visto, asilo político, refúgio, autorização de residência, nacionalidade e naturalização, extradição e infrações e respectivas penalidades. 
Observa-se que significativa parte da doutrina (BRASIL,GODINHO,2020,p.73) assinala que o regulamento, ao longo de suas trezentos e dezenove disposições, por vezes consegue usurpar o papel da Lei $\mathrm{n}^{\mathrm{o}}$ 13.445/2017, chegando mesmo a inovar no sentido de diminuir o alcance de alguns dispositivos legais, o que resulta em restrição ilegítima ao ato normativo hígido e à vontade do legislador.

Cabe registrar também que os inúmeros vetos presidenciais representaram diminuições a importantes conquistas dos migrantes, e potencialmente violam o sistema interamericano de proteção ao qual se vincula o Estado brasileiro, sendo que o avanço da nova lei seria o reconhecimento pelo legislador ordinário dessa matriz, ao elaborar e construir o projeto de lei em total consonância às normas do direito internacional dos direitos humanos.

Nesse aspecto, denote-se que, na análise das ocorrências atuais de inúmeras migrações dos contingentes humanos, busca-se compreender os motivos desses "êxodos" e, principalmente, se eles não resultam ou incorrem em graves violações a direitos humanos, seja por parte dos estados dos quais emigram, como também por parte dos países que os recebem, seja quanto ao direito de asilo, para os que estão sendo perseguidos em seus locais de origem por motivação político-ideológica, ou seja por questões humanitárias diversas como a escassez alimentar, medicamentos, e a falta de pagamento pelo trabalho para manutenção digna das famílias e dos abrigamentos dados pelos países que os recebem, como o Brasil, sem uma estrutura que assegure o mínimo existencial, principalmente para os menores de idade.

Entretanto, a nova Lei de Migração não se encontra solitária na regulação jurídica do tratamento a ser aplicado a pessoas não nacionais presentes no território brasileiro de modo temporário ou permanente, mas faz parte de um conjunto de normas internas e internacionais que se aplicam à matéria, sobretudo depois da progressiva inserção do Brasil no sistema americano de direitos humanos ocorrida depois do final dos governos militares.

\section{RECAPITULAÇÃO DA POLÍTICA DE IMIGRAÇÃO BRASILEIRA DESDE O IMPÉRIO ATÉ O FIM DOS GOVERNOS DOS MILITARES}

No Brasil, cabe realizar uma abordagem pretérita para melhor verificação da sequência histórica da imigração, tendo como ponto do recorte o momento a partir da colonização portuguesa e em direção ao contexto atual.

Durante a colonização portuguesa, como registrado pela história, os habitantes locais, então denominados índios, originários mais antigos do continente, foram 
progressivamente dizimados nos confrontos com o avanço colonizador da coroa portuguesa voltado para a exploração do território no sentido de auferir riquezas para benefício da metrópole e mesmo o custeio do esforço colonizador. Em paralelo, iniciou-se no período colonial o traslado forçado dos negros africanos, que, na sua terra natal, eram capturados em grandes contingentes populacionais, e transformados em imigrantes forçados, na "categoria de escravos" e que, depois do término da barbárie em face de seus direitos humanos, simplesmente foram deixados ao abandono sócio-econômico pelo governo brasileiro já independente. Desse modo, essas populações, de origem não europeia, não foram assimiladas, pelo novel Estado, como destinatários dos aparatos instituto-governamentais, seja como nacionais ou cidadãos.

As políticas imigratórias que surgiram desde o início do novo império sul-americano voltaram-se para o incentivo de atração de imigrantes europeus e no intuito de embranquecer a população local, malgrado a notória existência desses contingentes populacionais de escravos e libertos (FRAZÃO,2017,p.1106), disponíveis para eventual esforço sócio-econômico, desde que assimilados como componentes isonômicos na nacionalidade.

O viés europeu dessa política imigratória pode ser verificado desde as primeiras disposições legais implantadas no país, a exemplo da Decisão nº 80 de 1824 do Imperador Pedro I, que destinava terras para colonos alemães em São Leopoldo (BRASIL, GODINHO, 2020, p. 61) hoje situado no Estado do Rio Grande do Sul, e na pioneira Lei de Terras $n^{\circ}$ 601/1850, que buscava incentivar a concessão de terras para imigrantes.

Registre-se que nesse período imperial permanecia constante a chegada de contingentes de africanos escravizados, malgrado a vigência de tratado com a Inglaterra, desde 1826, que proibia o tráfico de escravos e que somente veio a ser reduzido depois da Lei Eusébio de Queiroz em 1850, impulsionada pelo Bill Aberdeen, votada no parlamento da Inglaterra (GALINDO, DEL NEGRO,2015, p.21).

Durante a primeira república, a política imigratória não se alterou, como se verifica

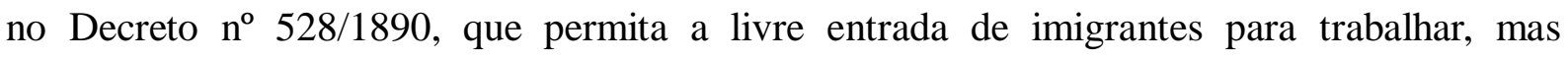
desestimulava populações oriundas da Ásia, África e indígenas, e do Decreto no 9.081/1911, que implantava o serviço de povoamento no país (BRASIL,GODINHO,2020,p.61) com promessas de terras e subsídios para imigrantes. 
Registre-se também que a Constituição da República de 1891 (art.72,\$10) não determinava nenhum controle documental para entrada e saída de nacionais ou estrangeiros do território nacional (ARAÚJO,2015,p.27), o controle de imigração e sua regulação, nos moldes próximos ao atual, veio a ser determinado apenas na Constituição de 1934 (art.113,§14), com exigência de passaporte e estipulações legais.

A interrupção da primeira república ocorre com a chamada revolução de 1930, na qual se implanta um regime autoritário comandado pelo proclamado Presidente Getúlio Vargas que, acompanhando as tendências históricas e da guerra daquele período, evolui para um regime ditatorial mais completo, então denominado Estado Novo, que prolongou o governo de Vargas até 1946.

Esse período se caracterizou pela centralização do poder, autoritarismo, nacionalismo e anticomunismo, com reflexos na indução de política imigratória restritiva, por se entender que imigrantes de determinadas nacionalidades como potenciais agentes das situações vividas em seus Estados de origem, representavam o perigo para a realidade brasileira. Nessa visão, o Estado Novo editou o Decreto $\mathrm{n}^{\circ} 3.010 / 1938$ que repelia pessoas ligadas a atividades políticas voltadas para ideologias de sindicalismo, anarquismo ou extremismos (FRAZÃO,2017, p.1111), e orientava a política imigratória pelo princípio da assimilação da cultura brasileira (FRAZÃO,2017, p.1112)

Finalizada a era Vargas, o regime democrático republicano restaurado prometia maior receptividade dos imigrantes, sobretudo considerando a necessidade de acolhimento para contingentes populacionais de diversos continentes afetados pela $2^{\mathrm{a}}$ guerra mundial, em busca de região mais promissora para recomeçar suas vidas.

A nova política imigratória, porém, veio a ser implementada pelo Decreto $\mathrm{n}^{\circ}$ 7.967/1945 que orientava uma imigração restritiva e dirigida (BRASIL,GODINHO,2020,p. 61), isto é, o imigrante havia de declarar um objetivo específico para a imigração e sua permanência estava condicionada à prática da atividade declarada, salvo eventual autorização das autoridades de imigração.

Esse decreto vigorou durante todo o período democrático até a implantação do regime militar em 1964, e se manteve durante esse regime até 1980, quando foi substituído pela Lei $\mathrm{n}^{\mathrm{o}}$ 6.815/1980, rotulada de Estatuto do Estrangeiro, ora revogada pela nova Lei de Migração, em adequação para com o regime democrático retomado no Brasil no final da década de 80 , 
ajustada com os princípios da $\mathrm{CF} / 1988$ e nas diretrizes internacionais de direitos humanos apresentadas desde o surgimento da Organização das Nações Unidas.

A antiga lei $n^{\circ}$ 6.815/1980, Estatuto do Estrangeiro, foi editada quando o regime militar, apesar de caminhar para o seu final melancólico, ainda fazia prevalecer a orientação pelo princípio da segurança nacional que dominava os governos ditatoriais do período, e sua denominação assinala a discriminação que realizava entre pessoas não nacionais em território brasileiro para diferenciar dos nacionais, bem como continha dispositivos que permitiam aos governantes se livrar de estrangeiros eventualmente ligados a atividades 'políticas' indesejadas, como se tentou aplicar na época a alguns sacerdotes católicos estrangeiros atuantes no Brasil, simpatizantes da teologia da libertação.

O cenário internacional, por sua vez, se mantinha favorável à vigência dessa lei, considerando a retomada da lógica da guerra fria pelo governo de Ronald Reagan nos EUA para com a URSS, e que abandonou as iniciativas internacionais de defesa dos direitos humanos praticadas pelo governo anterior de James Carter naquele país.

Em seguida, depois de finalmente encerrado de modo pacífico o regime militar no Brasil, os novos governos democráticos se conduziram pelo alinhamento com as diretrizes internacionais humanitárias e humanistas e orientação de uma política imigratória de acolhimento para pessoas não nacionais, como se verifica desde a Constituição de 1988 e depois pela Lei 9.474/94 e finalmente pela nova Lei de Migração.

\section{A CONSTITUIÇÃO DE 1988 E AS INOVAÇÕES EM DIREITOS HUMANOS PARA MIGRANTES}

A Constituição de 1988 restaura o caminho democrático do estado de direito no Brasil com a retomada dos compromissos com as convenções internacionais de direitos humanos, e, por conseguinte, mudança de rumo em direção ao acolhimento e garantia de direitos aos não nacionais em território brasileiro, induzindo obsolescência à Lei no 6.815/1980.

Quanto às relações internacionais, a $\mathrm{CF} / 88$ trouxe como inovação para com as constituições anteriores (DALLARI,2002,p.153) a declinação, no art. $4^{\circ}$, de princípios da atuação externa do governo brasileiro, que orientam, entre outras disposições, pela prevalência dos direitos humanos e em favor da concessão de asilo político, expressamente referido como princípio das relações exteriores (DALLARI,2002, p.180).

No sentido do alinhamento internacional com os direitos humanos, sobretudo na tendência de constituições latino americanas (MELLO,2001,p.2), o dispositivo mais agudo se 
encontra no art. $5^{\circ}, \S 2^{\circ}$, na parte final, que assume a recepção dos direitos e garantias dos tratados internacionais assinados pelo Brasil como extensão dos direitos e garantias expressos no texto positivo da Constituição.

Denote-se que o conteúdo da primeira parte do $\S 2^{\circ}$ do art. $5^{\circ}$ da $\mathrm{CF} / 88$ já constava na Constituição de 1946 (art. 144) e até mesmo foi repetido nas constituições outorgadas de 1967 (art.150,§35) e 1969 (art.153§36) que preservavam um capítulo de declaração de direitos individuais, certamente com intenção de manter aparências, porque essas 'constituições', em verdade, chancelavam no seu texto a plena validade dos atos institucionais exorbitantes então vigentes, proclamados pelos militares, que consistiam no efetivo aparato de governo, a exemplo do $\mathrm{AI} \mathrm{n}^{\circ}$ 13/1969, que autorizava o banimento de nacionais brasileiros.

Nessas declarações de direitos, os enunciados se iniciavam por conferir garantias aos estrangeiros, residentes no território brasileiro, de conteúdo muito semelhante ao caput do art. $5^{\circ}$, da CF/88, salvo pela menção expressa do direito de igualdade.

A vedação de extradição de estrangeiros requerida por motivo de crimes políticos ou de opinião, registrada no art. 5º LII da CF/88, também já constava da Constituição de 1946 (art. 141, §33) e foi repetida nas 'constituições' outorgadas. Porém, a Constituição de 1946 continha dispositivo (art.143) que permitia a expulsão de estrangeiros nocivos à ordem pública, repetindo, nesse aspecto, dispositivo da Constituição de 1934 (art.113,§15).

Entretanto, o sustento normativo e ideológico para o conteúdo do Estatuto do Estrangeiro se encontrava no capítulo dedicado à Segurança Nacional, incluso tanto no texto de 1967 como no texto de 1969 entre as atribuições para o Poder Executivo (Capítulo VII), que, repudiado na $\mathrm{CF} / 88$, tornou distorcida a permanência da lei ${ }^{\circ}$ 6.815/1980 na vigência plena da $\mathrm{CF} / 88$.

Todavia, antes da substituição dessa lei, outros passos foram caminhados para aproximação da política imigratória nacional das diretrizes humanistas internacionais, a exemplo da lei $n^{\circ}$ 9.474/1997, dedicada a estabelecer e disciplinar o acolhimento de refugiados no Brasil.

\section{DESTAQUES DA POLÍtica MigRATÓRIA BRASILEIRA POSTERIOR AO PERÍODO MILITAR}

A mudança de rumo quanto ao acolhimento de não nacionais no território brasileiro se inicia efetivamente no processo de redemocratização do governo de José Sarney, mas antes disso, ainda durante regime militar, ocorrem fatos relevantes nessa direção pela instalação do 
escritório da ACNUR - Alto Comissariado das Nações Unidas para Refugiados no Brasil, em 1982 (MILESI,ANDRADE,2010, p.29), bem como, no ambiente latino-americano, a proclamação da Declaração de Cartagena de 1984, em reforço do compromisso dos países latino americanos para com as convenções para refugiados da ONU.

O governo Sarney passa aplicar uma política imigratória de preferencial acolhimento de estrangeiros (UEBEL,RANINCHESKI, p.92) de diversas origens e por diversos motivos, buscando não somente demarcar a mudança de ação para as características de um governo civil, como também restaurar entrosamento com as diretrizes democráticas e humanistas emanadas das relações internacionais, sobretudo através da ONU e da OEA.

Os governos seguintes de Fernando Collor e seu sucessor forçado, Itamar Franco, prosseguiram na mesma orientação para a política imigratória. Os destaques principais desse período nas relações internacionais se encontram na assinatura do Tratado de Assunção em 1991 pelo presidente Fernando Collor, que implementa o MERCOSUL, e sobretudo a efetivação no ordenamento interno da CADH - Convenção Americana dos Direitos Humanos, Pacto de São José da Costa Rica, ratificado pelo Brasil em 25/09/1992 e promulgado no Decreto $n^{\circ}$ 678, de 06/11/1992, emitido pelo Vice-Presidente Itamar Franco, então já em exercício da Presidência da República.

Registre-se que ambas as iniciativas se ressaltam como ajuste de compatibilidade do ordenamento para com a então novata Constituição de 1988, porque a criação do MERCOSUL atende à diretriz do art. $4^{\circ}$, parágrafo único, e a promulgação da CADH se ajusta com a parte final do art. $5^{\circ}, \S 2^{\circ}$, pela confirmação de compromisso com relevante convenção humanitária regional.

O governo de Fernando Henrique Cardoso eleito em 1994, assim como o de seus antecessores civis, segue o mesmo roteiro de alinhamento humanitário de orientação internacional, porém, avança um passo importante no acolhimento de pessoas não nacionais, com a edição da lei $n^{\circ} 9.474$ de 22/07/1997, que define mecanismos para implemento no Brasil do Estatuto dos Refugiados de 1951 da ONU.

Antes da edição do estatuto dos refugiados a atenção a essas populações era realizada por ações de instituições religiosas como a Conferência Nacional de Bispos do Brasil - CNBB e Caritas, organização não governamental da Igreja Católica mantida pela CNBB, entidades da sociedade civil como a OAB e beneficentes (MILESI, ANDRADE,2010, p.33) 
Essa lei vinha preencher uma lacuna no ordenamento interno brasileiro, uma vez que a lei $n^{\circ} 6.815 / 1980$ não tratava da matéria dos refugiados, embora o Brasil fosse signatário, desde 1961, da Convenção sobre o Estatuto dos Refugiados adotada em Genebra em 28 de julho de 1951, bem como do complementar Protocolo sobre o Estatuto dos Refugiados, adotado em Nova York em 31 de janeiro de 1967, vigente desde 4 de outubro de 1967, promulgado no Brasil em 1972.

$\mathrm{Na}$ lei $\mathrm{n}^{\circ}$ 9.474/1997 o termo refugiado identifica pessoa solicitante de refúgio que enfrenta graves situações de violações de seus direitos humanos no seu local de origem, que não pode resistir nem obter apoio em seu próprio Estado, e não lhe resta alternativa, senão de empreender fuga para assegurar sua própria sobrevivência e da sua família.

Cabe assinalar que os parentes próximos e demais integrantes do núcleo familiar da pessoa atingida pela violação, ainda que não sejam diretamente atingidos pela mesma perseguição, podem receber a mesma proteção aplicada ao solicitante, uma vez que o legislador, de forma acertada e equânime, incluiu a possibilidade do nominado 'refugiado por extensão' no art. $2^{\circ}$ da Lei $n^{\circ} 9.474 / 1997$, estendendo também para a família do refugiado a proteção deferida pelo sistema internacional protetivo.

Registre-se ainda que a regulamentação para migrantes e refugiados presentes no território brasileiro, cujas situações jurídicas não se confundem, recebeu relevante complemento pela edição do Decreto n $n^{\circ}$ 9.277, de 05/02/2018, que instituiu o Documento Provisório de Registro Nacional Migratório, que também se aplica ao reconhecimento formal da condição de refugiado.

As legislações referidas, portanto, inspiradas nas normas internacionais, representam a adesão brasileira ao um efetivo sistema universal e regional protetivo para refugiados.

Além da lei para refugiados, o governo de FHC também prossegue na aproximação ao alinhamento com as diretrizes internacionais de direitos humanos, e realiza outra iniciativa relevante, ao promulgar no Decreto $n^{\circ}$ 4.463/2002 a declaração de compulsoriedade no Brasil dos julgamentos e decisões da Corte Interamericana dos Direitos Humanos, órgão judiciário internacional vinculado da Convenção da CADH.

O governo do Presidente da República Luís Inácio da Silva - Lula manteve o alinhamento humanitário internacional de seus predecessores com ênfase na abordagem de viés social, que expressa o diferencial da corrente política que representa, e nesse sentido, reformulou as bases institucionais de seu programa de governo pela criação de algumas 
secretarias de conteúdo social, vinculadas à Presidência da República, entre elas a Secretaria de Direitos Humanos (UEBEL,RANINCHESKI,2017,p. 93)

Todavia, o evento dominante do período consistiu no início da participação na intervenção da ONU no Haiti na liderança da operação MINUSTAH, que durou desde 2004 até 2017 , sob organização essencialmente militar, com objetivo humanitário, de pacificação e reorganização institucional daquele país.

Essa participação brasileira na operação da ONU no Haiti induziu um primeiro fluxo migratório de haitianos para o Brasil, sobretudo depois do terremoto de 2010, que acentuou as carências humanitárias daquela população sofrida, em deslocamento forçado que durou até 2015 (SPINELLI, BRAGA,2017, p.608). Esse fluxo migratório que afetou o primeiro período do governo da Presidente da República Dilma Rousseff induziu o implemento do visto especial humanitário, criado em 2012, para atender melhor as demandas de acolhimento desses migrantes. (UEBEL, RANINCHESKI, 2017, p. 93)

Outro evento significativo de referência com migrantes e refugiados se verifica na promoção da reunião de revisão da Declaração de Cartagena de 1984, ocorrida em Brasília em 2014 e denominada como "Cartagena + 30", que resultou na aprovação por países da América Latina e Caribe da Declaração do Brasil e Plano de Ação dos países da região no sentido de proteção de refugiados, deslocados e apátridas.

A interrupção excepcional do segundo governo de Dilma Rousseff deu origem a governo de Michel Temer, que foi marcado pela declaração de continuidade e pretensão de articulação interministerial, mas que permaneceu agitado pelas sequelas dos problemas políticos antecedentes. No que diz respeito a migrantes e refugiados, o período enfrentou um segundo fluxo migratório, dessa vez de venezuelanos afugentados pela crise sócio-econômica no país vizinho (UEBEL,RANINCHESKI, 2017, p.107)

No primeiro momento, o governo de Temer reagiu com ações de restrição de controles de fronteiras e com deportações, porém, mais adiante, cedeu aos motivos humanitários e promoveu em 2018 a chamada Operação Acolhida, organizada pelo Exército e ainda em curso, com objetivo de acolhimento, abrigamento e imigração controlada desse fluxo de pessoas para o território brasileiro.

6. A ADESÃO DO BRASIL À CADH - CONVENÇÃO AMERICANA DE DIREITOS HUMANOS E SEUS EFEITOS PARA MIGRANTES 
A adesão completa brasileira ao sistema americano de direitos humanos ocorreu em etapas nas quais, por primeiro houve a ratificação da $\mathrm{CADH}$, em seguida o reconhecimento da efetividade da jurisdição da CIDH, e nesse ínterim a adesão ao Protocolo de San Salvador,

Denote-se que a CADH, Pacto de San José de Costa Rica, consiste numa Convenção com duas partes, na Parte I estão declinados os direitos e garantias deferidos aos cidadãos dos países aderentes, membros da OEA, e na Parte II estão instituídos os órgãos de proteção e efetividade para as garantias, representados na Comissão Interamericana de Direitos Humanos e a Corte Interamericana de Direitos Humanos. A primeira com função de estímulo, cooperação e recomendações aos Estados-membros no âmbito da Convenção e a última com função de apreciar e julgar causas referentes a violações de direitos humanos, por resposta de consultas ou emissão de decisões de eficácia compulsória para as partes signatárias.

A Convenção Americana de Direitos Humanos, foi concluída e assinada em 1969 na cidade de San José da Costa Rica que lhe cede o nome, sob patrocínio da OEA, e determina que sua vigência (art. 74, item 2) seria iniciada tão logo se contassem 11 manifestações de ratificação ou adesão de países membros. No caso, sua vigência internacional acontece somente em 1978, nove anos depois. Recorde-se, nas razões para esse retardo, os interesses e políticas orientadas pela lógica da Guerra Fria que afetavam vários governos de Estados da região, muitos deles configurados em ditaduras militares.

No Brasil não era diferente, e os governos dos militares que duraram até 1984 não se interessaram pela promulgação, que veio a ocorrer apenas em 1992, cerca de trinta e três anos depois da conclusão da convenção, quando já encerrado o regime militar. Destaque-se ainda que, quando da adesão em 1992, o governo brasileiro registrou declaração interpretativa que condicionava as visitas e inspeções locais à anuência expressa do estado membro.

Em adendo, registre-se que a introdução completa da Convenção Americana de Direitos Humanos no ordenamento nacional ocorreu somente no ano de 1998, quando editado o Decreto Legislativo n. 89, reconhecendo a compulsoriedade da jurisdição da Corte Interamericana de Direitos Humanos, instituída na Parte II da Convenção e, portanto, tornando obrigatório o cumprimento de suas decisões. A aprovação da compulsoriedade dos julgamentos da Corte vem a ser promulgada apenas alguns anos depois com o Decreto $\mathrm{n}^{\circ}$ 4.463 de 08.11.2002.

Durante esse período, cabe registrar também a conclusão em 17/11/1988 do Protocolo de San Salvador - Protocolo Adicional à $\mathrm{CADH}$, em Matéria de Direitos Econômicos, Sociais 
e Culturais, que estende a abrangência de proteção do sistema americano para os chamados direitos humanos de $2^{\mathrm{a}}$ geração, no que acompanhou a iniciativa da ONU de complementar seu sistema universal de direitos humanos, através da emissão do PIDC - Protocolo Internacional sobre Direito Civis e Políticos e PIDESC - Protocolo Internacional sobre Direitos Econômicos, Sociais e Culturais, vigentes desde 1976, aderidos pelo Brasil em 1992.

O Protocolo de San Salvador, tal como a CADH, demandava a adesão de 11 signatários para entrar em vigor (art. 21, item 3) e por isso delongou por 11 anos para alcançar a vigência somente em 16/11/1999, nesse caso, também atingindo o Brasil que aderiu ao Protocolo em 21/08/1996, depois da aprovação no Decreto Legislativo $n^{\circ}$ 56/1995, e veio a ser promulgado pelo Decreto $\mathrm{n}^{\circ} 3.321$, de 30/12/1999.

Essa adesão completa do Brasil insere o país com perfeição a um vislumbrado sistema regional de direitos humanos, coroado pela $\mathrm{CADH}$, esta por sua vez, inspirada e afinada com o sistema universal de direitos humanos, representado pela Organização das Nações Unidas - ONU, sua Comissão de Direitos Humanos e demais órgãos afins.

De fato, a sobreposição e integração dos dois sistemas se revela como parte do fenômeno de irradiação universal humanista do pós-guerra, uma vez que os instrumentos jurídicos anteriores, interpretados em excessivo positivismo findaram por 'justificar' regimes totalitários e conviver com graves violações de direitos humanos, quando então a hermenêutica de momento das leis, acolheu a validade até mesmo de crimes contra a humanidade, determinados por dirigentes ou grupos políticos radicais. No contexto latinoamericano, essas ações extremistas de governos se justificavam em nome do combate ao comunismo ou socialismo, e não raro se estabeleceram depois da destituição de governantes democráticos legitimamente eleitos.

Por sua vez, no âmbito do direito interno brasileiro, depois da proclamação da Constituição de 1988, temos a possibilidade expressa de acolhimento de novas normas internacionais que o Estado Brasileiro venha a celebrar, sobretudo em matéria dos direitos fundamentais, conforme expressamente autorizado no art. $5^{\circ}, \S 2^{\circ}$ da CF88 com reflexos oriundos da Declaração Americana dos Direitos e Deveres do Homem, que passaram cada vez mais a serem impregnados na aplicação judicial dos textos constitucionais.

\subsection{O Artigo 22 da Convenção Americana de Direitos Humanos}

No que diz respeito ao deslocamento e acolhimento de pessoas, a CADH estipula preceitos específicos dos direitos humanos dos migrantes, como se verifica no art. 22, 
independente de se tratar de nacionais de determinado país sul-americano ou mesmo um apátrida, mas tão somente em atenção a sua condição humana, para a qual deve se voltar a proteção e garantia dos ordenamentos jurídicos nacionais, que não podem ser esquecidos ou afastados sob qualquer argumento de governo, em respeito ao princípio da dignidade humana.

\begin{abstract}
Artigo 22. Direito de circulação e de residência
1. Toda pessoa que se ache legalmente no território de um Estado tem direito de circular nele e de nele residir em conformidade com as disposições legais.

2. Toda pessoa tem o direito de sair livremente de qualquer país, inclusive do próprio.

3. $O$ exercício dos direitos acima mencionados não pode ser restringido senão em virtude de lei, na medida indispensável, numa sociedade democrática, para prevenir infrações penais ou para proteger a segurança nacional, a segurança ou a ordem públicas, a moral ou a saúde públicas, ou os direitos e liberdades das demais pessoas.

4. $O$ exercício dos direitos reconhecidos no inciso 1 pode também ser restringido pela lei, em zonas determinadas, por motivo de interesse público.

5. Ninguém pode ser expulso do território do Estado do qual for nacional, nem ser privado do direito de nele entrar.

6. O estrangeiro que se ache legalmente no território de um Estado Parte nesta Convenção só poderá dele ser expulso em cumprimento de decisão adotada de acordo com a lei.

7. Toda pessoa tem o direito de buscar e receber asilo em território estrangeiro, em caso de perseguição por delitos políticos ou comuns conexos com delitos políticos e de acordo com a legislação de cada Estado e com os convênios internacionais.

8. Em nenhum caso o estrangeiro pode ser expulso ou entregue a outro país, seja ou não de origem, onde seu direito à vida ou à liberdade pessoal esteja em risco de violação por causa da sua raça, nacionalidade, religião, condição social ou de suas opiniões políticas.

9. É proibida a expulsão coletiva de estrangeiros.
\end{abstract}

Não custa recordar que o estudo tradicional de um ordenamento normativo nacional de um país se inicia pela abordagem do Direito Constitucional, matéria de topo do sistema jurídico interno, que instrui a elaboração e aplicação das normas ordinárias, e representa a autonomia de um Estado para elaborar suas próprias normas gerais, com soberania para com outros países. Contudo, a abordagem se altera quando se observa a condição de um país independente como membro integrado de uma 'Sociedade Internacional', que implica uma nova concepção do poder soberano, não mais entendido como absoluto, mas sujeito a limites demarcados em termos convencionais na esfera internacional, sobretudo em se tratando de direitos humanos. (BONAVIDES,2004, p.586).

Da mesma forma como acontece com um indivíduo, pessoa, que assimila que, ao fazer parte da população de um país, delega a seus representantes do parlamento, do executivo e do judiciário, o poder para elaborar e fazer cumprir as normas gerais, no âmbito interno Estado de Direito de cada país, no momento em que um Estado adere a uma Convenção, a exemplo do Pacto de San José da Costa Rica, ou celebra um tratado que versa sobre Proteção 
a Direitos Essenciais da Pessoa, torna-se submetido à eventual competência de um tribunal internacional especializado para matéria de direitos humanos, como sucede no âmbito regional com a Corte Interamericana de Direitos Humanos, que efetivamente restringe sua capacidade de deliberar sobre todos os assuntos de seus interesses, principalmente no que diz respeito à proteção e garantia da dignidade humana.

No sistema regional interamericano, os dispositivos de Direitos Humanos referentes ao acolhimento, asilo e liberdade de trânsito dos migrantes, recebem menção expressa na CADH - Pacto de San José da Costa Rica, no seu artigo 22.

\subsection{Da Submissão Compulsória às Diretrizes do Sistema Americano de Direitos Humanos}

Depois de visto o percurso histórico das políticas brasileiras de recepção e acolhimento de pessoas não nacionais, cabe observar a realidade atual dos fluxos migratórios sul-americanos, que reclama do Brasil, como um dos líderes do Mercosul e considerável relevância no ocidente do globo terrestre, uma atenção especial para os migrantes, devendo haver por parte dos governos a determinação aos órgãos de administração, com atribuição nessa área, a instituição de política de acolhimento institucional, sendo recomendada a interpretação mais favorável à Lei 13.445/2017, inclusive afastando eventuais dispositivos do seu regulamento, Decreto $\mathrm{n}^{\circ}$ 9.199/2017, mais restritivos que a norma legislada, que porventura embaracem a aproximação progressiva do ordenamento brasileiro para como o sistema regional de direitos humanos.

Recorde-se que o Estado brasileiro aderiu voluntariamente ao sistema internacional de direitos humanos, que, em termos regionais, se constitui a partir da $\mathrm{CADH}$, que apresenta como características específicas a compulsoriedade e a irrenunciabilidade.

Nesse sentido, registre-se o Parecer Consultivo, ou Opinião Consultiva, OC-2518, de 31.05.2018, da Corte Interamericana de Direitos Humanos, com função enunciativa mas vinculante pelo conteúdo, que, antes de adentrar no cerne de consulta formulada pelo Estado do Equador quanto a questão da obrigatoriedade do acolhimento na forma de asilo, expressamente, asseverou sobre a impositividade das deliberações acerca dos direitos humanos aos Estados que já aderiram a Convenção.

Depois dessa adesão, o Estado Brasileiro assume o compromisso inarredável de manter fiel cumprimento, sob risco de, em caso contrário, sofrer sanções decorrentes de processos perante o órgão judicante por violações a direitos humanos. No que diz respeito a 
migrantes, cabe assegurar-lhes os direitos convencionados para com sua dignidade humana, a exemplo da livre circulação, entrar e sair, ter residência e acolhida pelos aparelhos de governo no solo nacional.

Nesse sentido, em nível internacional, considerando o disposto na Convenção Americana dos Direitos Humanos, sobretudo no seu artigo 22, deve haver o acompanhamento e fiscalização da Comissão Interamericana, através de agentes delegados ou inspetores para observação e relato das condições locais, considerando que a Comissão, inclusive, tem legitimidade para iniciar procedimentos em face do Estado, e a Corte pode adotar e aplicar as medidas judiciais cabíveis, sem mencionar eventuais medidas paralelas mais rápidas, como sanções comerciais, barreiras alfandegárias, e até mesmo instauração de processos para a apuração de responsabilidade de agentes políticos ou de governo.

Denote-se que, em se tratando de normas de direito internacional, a primeira atuação deve ser de forma preventiva, recomendando-se a adoção de medidas pelo Estado infrator. Em seguida, caso não obtido o resultado esperado de estancamento das violações de direitos humanos, cabe a aplicação de medidas coercitivas ou até mesmo ação repressiva, uma vez constatada a ocorrência prática, sobretudo nas hipóteses em que se configuram crimes contra a humanidade, como já houve precedentes em condenações de Cortes Internacionais no continente africano, Ruanda, e no continente europeu, Sérvia.

Importante frisar que tais medidas extremas somente devem ser adotadas para as condutas que, além de infringirem a Declaração Universal dos Direitos do Homem, resultam, pela sua gravidade, por ser o fato ensejador do êxodo desesperado de pessoas que, sem ter outra alternativa, acabam deixando tudo o que conquistaram para trás, entrando em notórias situações de risco e até se submetendo a condições deploráveis das suas próprias existências, para terem êxito na sua fuga.

Assim, no nosso atual contexto de migrantes sul-americanos, o posicionamento por parte Estado Brasileiro de uma eventual recusa em receber tais imigrantes e refugiados, na atual situação desta crise humanitária dentro de seu território, sobretudo no mais recente fluxo dos venezuelanos na unidade federativa de Roraima, poderia ser analisado e caracterizado como ensejador da atuação de normas do sistema regional de proteção dos direitos humanos dos migrantes, inclusive os que pleiteiam a concessão do asilo e refúgio.

Essa plausibilidade decorre do aceite de submissão à jurisdição de cortes internacionais de direitos humanos, por causa da adesão a tratados internacionais, e ser parte 
de organizações como ONU e OEA, cabendo a responsabilidade do Brasil, no caso de, apesar de tal acolhimento interno, não se prestar condições condignas de alojamento, salubridade e de mínimo de sobrevivência, ao numeroso contingente de seres humanos não nacionais, sem mencionar a necessidade de evitar o conflito social com a população da localidade.

Por conseguinte, diante da compulsoriedade das normas de Direitos Humanos e da submissão aos pronunciamentos da Corte Interamericana, torna-se necessário compreender a dinâmica dessa mobilidade humana e a diversidade dos fluxos migratórios, para aprimorar as respostas do Estado Brasileiro no que tange à política, legislação e governança institucional, tendo como premissa o acolhimento dos imigrantes, direito humano essencial, além do reforço, para esse mesmo fim, do compromisso com a cooperação regional.

\section{CONSIDERAÇÕES FINAIS}

$\mathrm{Na}$ análise desenvolvida, observamos que, desde o final dos governos militares, os governos brasileiros caminharam progressivamente no sentido de reintegrar o Brasil ao sistema internacional de direitos humanos, e para isso foram editadas legislações internas ajustadas às diretrizes internacionais e promovida a adesão completa às convenções regionais.

O resultado final desse progresso, ainda que inacabado, consistiu na edição da nova Lei de Migração, lei n ${ }^{\circ}$ 13.445/2017, que, embora parcial e indevidamente restringida pelo seu regulamento, Decreto n 9.199/2017, não está desacompanhada nas suas disposições de favorecimento ao tratamento humanista digno para com migrantes, deslocados e refugiados porventura presentes no território brasileiro, porque o ordenamento nacional se encontra integrado com as convenções humanistas americanas de modo consolidado.

$\mathrm{Na}$ realidade latino-americana estão ocorrendo grandes movimentações de contingentes populacionais, por causa das condições dramáticas nos seus países de origem, que acorrem em busca sobretudo dos EUA, mas também ao Brasil, ainda que de passagem, boa parte deles classificáveis como refugiados, asilados ou apátridas, migrantes portadores de vistos de entrada ou mesmo irregulares.

Além das populações afluentes regionais, adicionam-se contingentes deslocados de outras regiões como sírios e africanos ocidentais de língua portuguesa, tangidos pelas mesmas desconstruções de seus locais nativos.

No Brasil, esses contingentes são desassistidos de políticas institucionais permanentes e se tornam alvos de falsas divulgações que vinculam os imigrantes a fatores como aumento da criminalidade, de desagregação social, que induzem um sentimento 
xenófobo e da construção indesejável de guetos com outros conterrâneos, como ocorre em outros países.

Ora, o Estado Brasileiro se encontra impedido de se recusar a cumprir as normas internacionais às quais está vinculado, e além ter o dever de dar o acolhimento, deve buscar a integração progressiva desses contingentes com a população nacional, inclusive através de políticas educacionais para combater esse preconceito (xenofobia).

Cumpre destacar, assim, que a Corte Interamericana de Direitos Humanos, pode imputar ao Brasil o cumprimento desse dever humanitário, que, inclusive, pode ser acionada em face de qualquer um dos Estados que a referendaram internamente em seus ordenamentos jurídicos, com lastro em princípios, tais como o livre direito de circulação de migrantes, dignidade da pessoa humana e solidariedade universal, já reconhecidos em vários tratados, como no Pacto de San Jose da Costa Rica e julgamentos de Cortes Internacionais de Direitos Humanos da Organização das Nações Unidas.

\section{REFERÊNCIAS}

ARAÚJO, Natalia Medina. Migrantes indocumentados: histórias e aporias, in Migrações, Deslocamentos, e Direitos Humanos. Org. George R B Galindo, p. 25-34. Brasília. IBDC. 2015.

BONAVIDES, Paulo. Curso de Direito Constitucional, 14. ed, São Paulo: Malheiros, 2004.

BRASIL. Constituição de 1891. Disponível em: 〈http://www.planalto.gov.br〉. Acesso em: 10/03/2021.

BRASIL. Constituição de 1934. Disponível em: <http://www.planalto.gov.br>. Acesso em: 10/03/2021.

BRASIL. Constituição de 1946. Disponível em: <http://www.planalto.gov.br>. Acesso em: 10/03/2021.

BRASIL. Constituição de 1967. Disponível em: <http://www.planalto.gov.br>. Acesso em: 10/03/2021.

BRASIL. Constituição de 1969. Disponível em: <http://www.planalto.gov.br>. Acesso em: 10/03/2021.

BRASIL. Ato Institucional $\mathrm{n}^{\circ} 13$ de 05 de setembro de 1969. Disponível em: <http://www.planalto.gov.br>. Acesso em: 10/03/2021.

BRASIL. Constituição de 1988. Disponível em: <http://www.planalto.gov.br>. Acesso em: 10/03/2021.

BRASIL, Deilton Ribeiro; GODINHO, Ana Paula de Pinho. Uma Leitura do Contexto Histórico das Políticas Migratórias Brasileiras e das Disposições Preliminares da Nova Lei de Migração. Revista PPGD, v. 30, n.2, jul-dez 2020, p. 59-78. Salvador: Ed. UFBA, 2020

CAMPOS, Barbara Pincowska Cardoso; SILVA, João Guilherme Lima Granja Xavier da Igualdade, não discriminação e política para migrações no Brasil: antecedentes, desafios e potencialidades para o acesso da pessoa migrante a direitos e serviços, in Migrações, Deslocamentos, e Direitos Humanos. Org. George R B Galindo, p.50-63. Brasília:IBDC. 2015 DALLARI, Pedro. Constituição e Relações Exteriores. São Paulo: Saraiva, 1994. 
FRAZÃO, Samira Moratti. Política (i)migratória brasileira e a construção de um perfil de imigrante desejado: lugar de memória e impasses. Antíteses,v.10,n.20, p.1103-1128. Londrina: Ed. UEL, 2017.

GALINDO, George Rodrigo Bandeira; DEL NEGRO, Guilherme. Lições Modernas (e algumas não tanto) do Tráfico Atlântico de Escravos, in Migrações, Deslocamentos, e Direitos Humanos. Org. George R B Galindo, p. 10-24. Brasília: IBDC. 2015.

MELLO, Celso de Albuquerque. O Parágrafo $2^{\circ}$ do art $5^{\circ}$ da Constituição Federal, in Teoria dos Direitos Fundamentais, 2. ed, Org. Ricardo Lobo Torres, p. 1-33. Rio de Janeiro: Renovar, 2001.

MILESI, Rosita Irmã; ANDRADE, William Cesar de. Atores e Ações por uma Lei de Refugiados no Brasil, in Refúgio no Brasil: a proteção aos refugiados e seu impacto nas Américas. Org. Luiz Paulo F Barreto. Brasília: ACNUR/MJ. 2010.

MORAES, Thais Guedes Alcoforado de. O Princípio da Não Devolução de Refugiados à luz do sistema interamericano de direitos humanos, in Migrações, Deslocamentos, e Direitos Humanos. Org. George R B Galindo, p. 35-49. Brasília: IBDC. 2015.

SPINELLI, Fabiana Braun; BRAGA, Andrea da Costa. Integração sócioespacial de imigrantes haitianos na cidade de Lajeado, Brasil: um estudo configuracional, in Migrações Históricas e Recentes. Org. Tiago Weizenmann, Rodrigo Luís dos Santos, Caroline von Mühlen, p. 605622. Lajeado: Ed. Univates, 2017. Acesso em: 10.03.2021

UEBEL, Roberto Rodolfo Georg; RANINCHESKI, Sonia Maria. Uma Ponte para o Futuro?: as migrações internacionais na agenda governamental brasileira. Perfis, agendas e tratamentos, in Migrações Históricas e Recentes. Org. Tiago Weizenmann, Rodrigo Luís dos Santos, Caroline von Mühlen, p. 90-115. Lajeado: Ed. Univates. 2017. Acesso em: 10.03.2021 